\title{
Peripheral myelin protein-22 (PMP22) modulates alpha 6 integrin expression in the human endometrium
}

\author{
Rajiv G Rao ${ }^{1 \dagger}$, Deepthi Sudhakar ${ }^{1 \dagger}$, Claire P Hogue', Stephanie Amici², Lynn K Gordon ${ }^{3}$, Jonathan Braun ${ }^{1,4}$, \\ Lucia Notterpek ${ }^{2}$, Lee Goodglick ${ }^{1,4}$ and Madhuri Wadehra ${ }^{1 *}$
}

\begin{abstract}
Background: PMP22, a member of the GAS3 family of tetraspan proteins, is associated with a variety of neurological diseases. Previous studies have shown that PMP22 is expressed in proliferative endometrium, but its function within this tissue is poorly understood. In this study, we first characterized the expression of PMP22 in the human menstrual cycle and began to characterize its function in the endometrium.

Methods: Using a combination of immunohistochemistry and quantitative PCR, we characterized the expression of PMP22 in both proliferative and secretory endometrium. Differences in PMP22 expression between proliferative and secretory endometrium were determined using a Mann-Whitney $U$ test. In order to investigate the influence of PMP22 on $\alpha 6$ integrin expression, cells were created that ectopically overexpressed PMP22 or expressed a siRNA to inhibit its expression. These cells were analyzed for changes in integrins and binding to extracellular matrices.

Results: In this study, we show that PMP22 expression is higher in proliferative phase than secretory phase. Functionally, we have begun to characterize the functional significance of this expression. Previous studies have suggested a link between PMP22 and $\alpha 6$ integrin, and therefore we asked whether PMP22 could associate or potentially modulate the expression of $\alpha 6$ integrin. Expression of both PMP22 and $\alpha 6$ integrin were detectable in endometrial epithelial and stromal cells, and we show that both proteins can associate and colocalize with each other. To understand if PMP22 directly altered the expression of a6 integrin, we examined cell lines with modulated levels of the protein. Overexpression of PMP22 was sufficient to increase $\alpha 6$ integrin surface expression with a concominant increase in binding to the extracellular matrix laminin, while a reduction in PMP22 suppressed $\alpha 6$ integrin surface expression.
\end{abstract}

Conclusion: These findings suggest a physiologic role for PMP22 on the expression of $\alpha 6$ integrin. We predict that this may be important for the maintainence of endometrial integrity and to the disease biology associated with altered levels of $\alpha 6$ integrin expression in the endometrium.

\section{Background}

Peripheral myelin protein 22 (PMP22) is a member of the Growth Arrest Specific 3 (GAS3) family of tetraspan proteins. Expression of the PMP22 gene is driven by two alternate promoters P1 and P2 which drive transcription for two transcripts containing different noncoding exons termed $1 \mathrm{~A}$ and $1 \mathrm{~B}$ [1]. Although both

\footnotetext{
* Correspondence: mwadehra@mednet.ucla.edu

† Contributed equally

'Department of Pathology and Laboratory Medicine, University of California, Los Angeles, California 90095, USA

Full list of author information is available at the end of the article
}

transcripts translate into identical proteins, the presence of two promoters is thought to confer tissue specific control of expression [2]. Transcripts arising from promoter 1 (termed 1A) have been shown in the peripheral and central nervous systems and are thought to be important for myelin formation [3,4]. Transcripts originating from promoter 2 (termed $1 \mathrm{~B}$ ) have been identified in neuronal and non-neuronal tissue throughout the body [1]. Within non-neuronal tissue, transcripts of PMP22 1B have been identified in the epithelia of the lungs and uterus, the choroid plexus, and the heart $[5,6]$.

\section{(Ciomed Central}


Translation of the PMP22 gene gives rise to a 160amino-acid protein, with four predicted transmembrane domains. The highest expression of PMP22 occurs in Schwann cells, and there, PMP22 localizes strictly with compact myelin [7]. Altered expression of PMP22 has grave consequences as it is associated with certain heritable demyelinating peripheral neuropathies. In particular, elevated expression of PMP22 causes CharcotMarie-Tooth disease type 1A (CMT1A), an autosomal dominant condition that is characterized by progressive motor and sensory polyneuropathy [8-10]. Haploinsufficiency of PMP22 results in hereditary neuropathy with liability to pressure palsies (HNPP) $[11,12]$.

Outside of its role in myelin formation, studies have implicated PMP22 in a number of cellular roles including adhesion and the regulation of proliferation [13]. In fact, PMP22 was first discovered as a gene upregulated in growth-arrested fibroblasts in culture [14], and since then, PMP22 protein has been shown to help regulate cell spreading and regulate apoptosis in these cells [15]. Its importance in non-neuronal cells was further expanded when it found that in epithelial cells, PMP22 localized within tight junctions and formed complexes with integrins such as $\alpha 6 \beta 4$ and with the integral cation channel P2X7 [16-18].

Several studies suggest a complex mechanism for the regulation of PMP22 expression, and recent studies have implicated steroid hormones in its regulation. Studies have shown that both progesterone and glucocorticosteroids act as positive regulators of expression in Schwann cells [19-21], and anti-progesterone therapy has been shown to reduce PMP22 levels, reducing the CMT1A phenotype [22,23]. However, outside of this cell type, limited information is available as to hormonal control of PMP22 expression. PMP22 has been observed in the uterus, with high PMP22 mRNA levels in proliferative stroma [24], but no studies have examined PMP22 expression in epithelial cells of the endometrium or throughout the estrous cycle.

In this study, we characterize the expression of human PMP22 during the proliferative and secretory phases of the female menstrual cycle. As previous studies have suggested that PMP22 associates with integrins, we generated human endometrial cell lines with varying levels of PMP22 expression and characterized their integrin profiles. We report for the first time, the expression of PMP22 protein in the human endometrium, with greater expression in the proliferative phase as compared to the secretory phase. Furthermore, we show that PMP22 colocalizes $\alpha 6$ integrin both in vitro and in normal human tissue samples. The dichotomy of PMP22 and $\alpha 6$ integrin expression in the female menstrual cycle suggests roles for the both proteins in adhesion and state of endometrial differentiation.

\section{Methods}

\section{Cell lines}

HEC-1A, Human endometrial adenocarcinoma cells (HTB112, ATCC, Manassas, VA) were cultured in McCoys media, supplemented with $10 \%$ fetal calf serum, $1 \%$ L-Glutamine, $1 \%$ penicillin/streptomycin at $37^{\circ} \mathrm{C}$ in a humidified $5 \% \mathrm{CO}_{2}$ incubator. Cells were passaged every 3-4 days. HEC-1A cells were stably transfected with expression plasmids for a control eGFP, or a human PMP22 open reading frame tagged with a myc-epitope in the second extracellular loop using FuGENE 6 (Roche Molecular Biochemicals) per the manufacturer's instructions. These expression vectors have been previously described [17,25]. Stable cellular clones were selected using Geneticin (800 ug/ml; Invitrogen, Carlsbad, CA) and referred to as HEC-1A/Vector (empty vector control), and HEC-1A/PMP22 (PMP22 overexpression). In some experiments, PMP22 levels were decreased by transiently transfecting HEC-1A cells with 75 picomoles PMP22 siRNA duplexes (SMARTpool L-010616-000005; ThermoScientific, Boulder, CO) and a lipophilic transfection reagent (Lipofectamine 2000; Invitrogen, Carlsbad, California) for 48 hours. As a negative control, cells were transfected with 75 picomoles scrambled control siRNA (D-001206-13-05; ThermoScientific). Cells were harvested for Western blot, flow cytometry, immunofluorescence or immunoprecipitations 36-48 hours post-transfection, as detailed below.

\section{Human tissue}

Retrospective human tissue was obtained from the UCLA Department of Pathology and Laboratory Medicine Tissue Procurement Core Facility (TPCL) under an exemption from the Institutional Review Board. To validate PMP22 expression in human endometrium, we tested total PMP22 expression in whole tissue fragments of proliferative endometrium $(n=6)$ and secretory endometrium $(n=6)$. As controls, we also obtained normal frozen tonsil and lung. Tissue samples were collected and frozen in the $-80 \mathrm{C}$. These tissues were prepared in the hospital biorepository, and clinical annotation is available though a database. Cases were classified and selected based on a normal diagnosis using the Anatomic Pathology system, and no information regulated by HIPPA was included in the study, which qualifies for the status of $\mathrm{NIH}$ Exemption \#4.

\section{RT-PCR}

All tissue was homogenized and RNA isolated using the Qiagen RNAeasy kit per manufacturer's instructions. The Qiagen OneStep RT-PCR kit (Valencia, CA) was employed using human PMP22 exon $1 \mathrm{~A}$ or $1 \mathrm{~B}$ [4] or GAPDH [26]-specific primers using $1 \mu \mathrm{g}$ RNA. 
PMP22 1A: 5'- TTACAGGGAGCACCACCA-3' PMP221B: 5'-CCACGCACCCGAGTTTGT-3' PMP22 R: 5'-ATCATGGTGGCCTGGACA-3'

The RT-PCR conditions were reverse transcribed at $50^{\circ} \mathrm{C}$ for $30 \mathrm{~min}$ followed by PCR $(25-40$ cycles $)$ at $95^{\circ} \mathrm{C}$ $(30 \mathrm{~s}), 55^{\circ} \mathrm{C}(30 \mathrm{~s})$, and $72^{\circ} \mathrm{C}(1 \mathrm{~min})$.

In order to quantititate mRNA levels, the Qiagen QuantiTect SYBR Green RT-PCR Kit was utilized. Primers were synthesized (Real Time Primers, Elkins Park, PA) which could recognize both transcripts of PMP22. The $25 \mu \mathrm{l}$ PCR reaction included $12.5 \mu \mathrm{l} 2 \times \mathrm{RT}$-PCR Master Mix, $0.5 \mu \mathrm{mol} / \mathrm{L}$ forward primer, and $0.5 \mu \mathrm{mol} / \mathrm{L}$ reverse primer. The reactions were incubated in a $96-$ well plate and reverse transcribed and amplied on the Applied Bio Systems7500 Fast System (Carlsbad, CA) using the following primers:

PMP22 F: 5' - GTATCATCGTCCACGTC-3'

PMP22 R: 5'-GGCAGAAGAACAGGAACAGA-3'

The $2^{-\Delta \Delta \mathrm{Ct}}$ method for relative quantification of gene expression was used to determine PMP22 expression levels [27]. Each sample was analyzed in triplicate, and the housekeeping gene GAPDH was used to normalize expression as previously described [28]. Differences between PMP22 expression in proliferative and secretory endometrium was determined using Mann-Whitney $U$ test.

\section{Western blot analysis}

Tissue or cell lines were lysed in Laemmli buffer as previously described [29] and analyzed for PMP22 expression by SDS-PAGE Western blot analysis. Approximately $25 \mu \mathrm{g}$ of protein were loaded per lane. In order to detect PMP22 expression, samples were treated for $2 \mathrm{~h}$ at $37^{\circ} \mathrm{C}$ with PNGase (New England Biolabs, Beverly, MA) to remove N-linked glycans [30]. Proteins were then separated by SDS-PAGE and transferred to a nitrocellulose membrane (Invitrogen). Following transfer, membranes were stained with Ponceau S (SigmaAlrich, St. Louis, MO) to validate the efficiency of transfer. A solution of $10 \%$ nonfat milk in Tris buffered saline containing $0.1 \%$ Tween- 20 was used to block nonspecific binding. Membranes were probed with rabbit anti-PMP22 antisera [6] or with anti- $\beta$-actin antibodies (Sigma-Aldrich). Protein bands were visualized using a horseradish peroxidase-labeled secondary antibody (Southern Biotechnology Associates, Birmingham, AL) followed by chemiluminescence (ECL; Amersham Biosciences). Band intensities were quantified using the NIH program Image J. Blots were digitized using a flatbed scanner and the band density measured using Image J. The relative intensity of PMP22 in the three cell lines was calculated by dividing the volume intensities over that of the $\beta$-actin control. Experiments were repeated three times and averaged.

\section{Immunoprecipitations}

Cells were washed in PBS and solubilized in lysis buffer for $30 \mathrm{~min}$ at $4{ }^{\circ} \mathrm{C}$. ( $1 \%$ Nonidet P-40 containing $2 \mathrm{mM}$ phenylmethylsulfonyl fluoride, $10 \mathrm{ug} / \mathrm{ml}$ aprotinin, $2 \mathrm{ug} /$ $\mathrm{ml}$ pepstatin, $10 \mathrm{mM}$ iodoacetamide, $0.1 \mathrm{mM}$ EDTA, 10 $\mathrm{mM}$ HEPES, and $10 \mathrm{mM} \mathrm{KCl})$. Lysates were sonicated for 15 seconds and pre-cleared by incubation with protein A-agarose beads (Santa Cruz Biotechnology, Inc., Santa Cruz, CA). Pre-cleared lysates were incubated overnight with Protein-A beads bound to either antiPMP22 rabbit polyclonal antisera (Sigma-Aldrich), anti$\alpha 6$ integrin rabbit polyclonal antibody (Santa Cruz Biotechnology), or control rabbit sera. The beads were washed once in lysis buffer and $50 \mathrm{mM}$ Tris buffer to neutralize salt. Immune complexes were eluted from the beads with Laemmli buffer. Cell lysates were subsequently analyzed by Western blots.

\section{Immunofluorescence}

HEC-1A cells were plated onto glass coverslips (Fisher Scientific, Pittsburgh, PA) and incubated for $24 \mathrm{~h}$ at $37^{\circ}$ C. Cells were fixed in cold methanol, blocked in $1 \%$ normal goat serum and washed in PBS with $0.01 \%$ Triton $\mathrm{X}-100$. Cells were subsequently incubated at $4{ }^{\circ} \mathrm{C}$ with PMP22 rabbit antisera (1:100; Sigma, CA), anti- $\alpha 6$ integrin rat antibody (1:100; BD Biosciences) in a humidified chamber. Cells were rinsed with PBS with $0.01 \%$ Triton $\mathrm{X}-100$, then incubated for 1 hour at RT with Alexa Fluro 488-conjugated goat anti-rabbit IgG (1:50), or fluorescein isothiocyanate (FITC)-conjugated anti-rat IgG2a (1:450; eBiosciences). Negative controls included incubation with secondary antibody alone. Cells were briefly washed in PBS with $0.01 \%$ Triton X-100, double deionized $\mathrm{H}_{2} \mathrm{O}$, and mounted onto slides in a $3.5 \% \mathrm{n}$ propyl gallate-glycerol solution. Mounted coverslips were analyzed for PMP22 and $\alpha 6$ integrin localization using confocal microscopy.

\section{Flow cytometry}

The membrane expression of $\alpha 6$ integrin, $\alpha 2$ integrin, and $\alpha \mathrm{v} \beta 3$ integrin were assessed by flow cytometry. Cells were fixed in $2 \%$ paraformaldehyde $(\mathrm{w} / \mathrm{v})$ in PBS for $20 \mathrm{~min}$ on ice. Cells were pelleted and resuspended in PBS with $2 \%$ fetal calf serum (FCS). Cells were incubated with primary antibody $(1: 100)$ and incubated at RT for $20 \mathrm{~min}$. Cells were then incubated with red-phycoerythrin-conjugated anti-rat Ig- $\kappa$ light chain antibody or red-phycoerythrin-conjugated anti-mouse Ig- $\kappa$ light chain antibody for $20 \mathrm{~min}\left(0.25 \mathrm{ug} / 10^{6}\right.$ cells; BD Biosciences). Negative control cells were treated similarly, but without primary antibody. After two consecutive washes with PBS, cells were resuspended in PBS and analyzed with a FACScan flow cytometer (BD Biosciences). Integrin expression levels were calculated as 
mean fluorescent intensity (MFI) using CellQuest software. Experiments were performed in triplicate.

\section{Immunohistochemistry}

Retrospective formalin fixed, paraffin embedded normal human proliferative or secretory endometrial samples were obtained from the TPCL at UCLA. Whole tissue sections of proliferative endometrium $(n=6)$ or secretory endometrium $(n=6)$ were analyzed by immunohistochemistry for PMP22 or $\alpha 6$ integrin expression. Briefly, paraffin-embedded human tissue samples were deparaffinized, blocked for endogenous peroxidase activity with $3 \%$ hydrogen peroxide, and heated at $95^{\circ} \mathrm{C}$ for 20 min with citrate buffer (19). The tissue samples were blocked with normal goat serum in TBS with Tween for $10 \mathrm{~min}$ and stained with rabbit-anti-PMP22 polyclonal antibody (1:100; Sigma-Aldrich) or anti- $\alpha 6$ integrin rabbit antibody (1:100; Santa Cruz Biotechnology Inc., Santa Cruz CA) overnight in a humidified chamber. Slides were developed by incubation with a biotinylated secondary antibody from the Vectastain Elite ABC kit (Vector Laboratories) according to the manufacturer's protocol, followed by a diaminobenzidine tetrahydrochloride (DAB) substrate solution (Pierce, Rockford, IL). Nuclei were counterstained with hematoxylin. Slides were analyzed for PMP22 and $\alpha 6$ integrin expression by microscopy.

To detail the staining of PMP22 and $\alpha 6$ integrin in proliferative and secretory endometrium, a semi-quantitative analysis was performed. Each section stained was assessed by considering the staining intensity $(0=$ below the level of detection, 1, weak; 2, moderate; and 3, strong) and the percentage of cells staining at each intensity level (0-100\%). For each tissue, an integrated value of intensity combined with frequency was derived using the formula: $[(3 \mathrm{x})+(2 \mathrm{y})+(1 \mathrm{z})] / 100$ where $\mathrm{x}, \mathrm{y}$, and $\mathrm{z}$ are $\%$ staining at intensity 3,2 , and 1 , respectively. Differences in expression between proliferative and secretory endometrium were determined using a MannWhitney test, where $\mathrm{p}<0.05$ was considered significant.

\section{Adhesion assays}

A standard static cell adhesion assay (15-20 min) was performed as previously described [30]. Briefly, 96-well plates were precoated for 2 hours at $37^{\circ} \mathrm{C}$ with the ECM substrates laminin, fibronectin, poly-D-lysine (positive control; Roche Molecular Biochemicals; 5-10 $\mu \mathrm{g} / \mathrm{ml}$ ), or $1 \%$ fatty acid-free bovine serum albumin (negative control; Sigma-Aldrich). Cells $\left(7 \times 10^{4}\right)$ were plated onto the ECM in serum-free conditions and incubated at $37^{\circ}$ $\mathrm{C}$ for $30 \mathrm{~min}$. Unbound cells were washed away. Bound cells were fixed, stained with toluidine blue and then lysed using 2\% SDS (Biowhittaker, Walkersville, MD). The resultant soluble toluidine blue was quantitated by measuring the absorbance at $595 \mathrm{~nm}$. Binding to each ECM was performed in triplicate. Each experiment was repeated at least three times. An unpaired Student's $t$ test was used to confirm significance between HEC-1A/ PMP22, HEC-1A/Vector, HEC-1A/scrambled siRNA control, and HEC-1A/PMP22 siRNA cells.

In antibody blocking experiments, cells were preincubated with various dilutions of anti- $\alpha_{6}$ integrin [31] or anti- $\alpha_{2}$ integrin [32] function blocking antibodies (BD Biosciences) for $60 \mathrm{~min}$ at $4^{\circ} \mathrm{C}$. Cells $\left(5-7 \times 10^{4}\right)$ were plated in triplicate into a 96 -well plate precoated with laminin or poly-D-lysine and allowed to adhere for 30 min. Unbound cells were washed away, and bound cells were quantitated as described above. Each experiment was repeated three times.

\section{Results}

\section{Characterization of PMP22 expression}

Previous studies have shown that PMP22 is expressed in proliferative endometrium [24]. In order to confirm the expression of PMP22 within the endometrium, we first confirmed the mRNA and protein expression of PMP22 in human endometrium. PMP22 expression has been shown to be regulated by two alternatively used promoters which are located upstream of two distinct 5 ' noncoding exons (exons $1 \mathrm{~A}$ and $1 \mathrm{~B}$ ), but both transcripts encode for a single protein $[3,33]$. To characterize both transcripts in the human endometrium, RT-PCR was performed on select human tissue. In the endometrium, PMP22 exon 1B mRNA expression was detectable, and this transcript was also found in low levels in the tonsil and in the lung (Figure 1A). Interestingly, PMP22 exon $1 \mathrm{~A}$ mRNA was only detectable in the lung. We next confirmed the protein expression of PMP22 using western blot and immunohistochemical analysis. PMP22 protein expression was observed in a representative human proliferative endometrial sample (Figure 1B) and within proliferative endometrial epithelial and stromal cells (Figure 1C).

In order to investigate the function of PMP22 in endometrial epithelial cells, we monitored PMP22 expression in a panel of endometrial cancer cell lines. Similar to the mRNA profile observed above, both HEC-1A and Ishikawa endometrial cell lines were positive for exon 1B expression (Figure 1D). The expression of PMP22 mRNA was below detection in RL95-2 cells. To translate PMP22 expression in these cells, we characterized the relative PMP22 protein expression by western blot analysis (Figure 1E). PMP22 was expressed in all three cell lines, with the highest expression observed in HEC-1A cells. Moreover, very low levels of PMP22 were observed in the RL95-2 cells.

To investigate the role of PMP22 in endometrial epithelial cells, we created a panel of HEC-1A cells with 


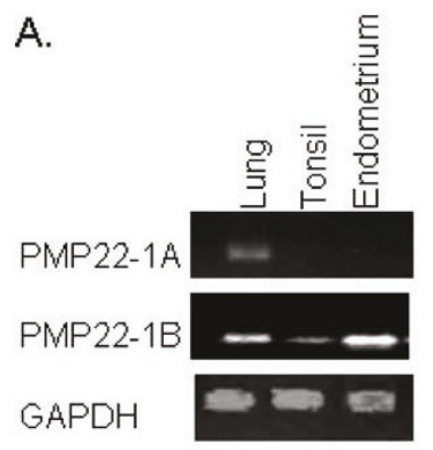

B.

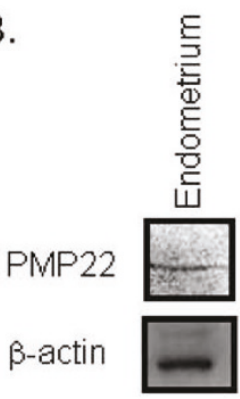

E.

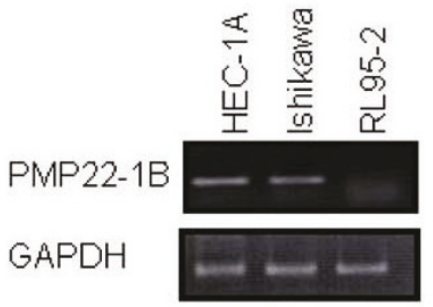

D.

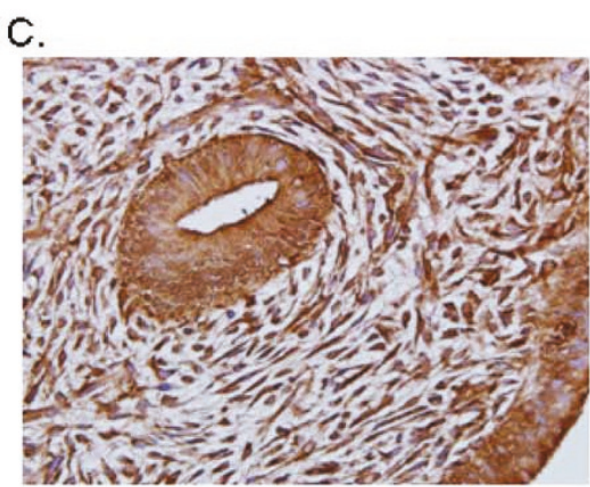

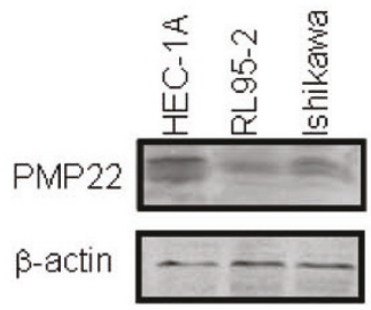

Figure 1 PMP22 is expressed in the endometrium. (A). Frozen adult human tissues were obtained, and total RNA isolated. PMP22 exon 1B mRNA was expressed in endometrium, lung, and tonsil tissue while expression of PMP22 exon 1B mRNA was only observed in the lung. GAPDH mRNA was used as the loading control. (B) Tissue lysates were prepared to determine PMP22 protein expression in the endometrium. PMP22 protein was detectable in proliferative endometrium, and a representative sample is depicted. $N=6$. (C) PMP22 expression was confirmed in human proliferative endometrium using immunohistochemistry, and a representative sample is displayed. $N=6$. Magnification $=400 \times$. (D) PMP22 mRNA transcripts were detected in HEC-1A, Ishikawa, and RL95-2 endometrial cell lines using semi-quantitative RT-PCR. GAPDH was used as a loading control. (E) PMP22 protein levels in the three immortalized endometrial cell lines were detected using PMP22 antisera. $\beta$-actin was used as a loading control. (E) To study PMP22 in HEC-1A epithelial cells, its expression was modulated through ectopic overexpression, or by inhibition using a PMP22 specific siRNA. Vector and scrambled siRNA controls are included for endogenous expression. Expression of PMP22 was confirmed by western blot analysis, with $\beta$-actin levels serving as a loading control. modulated PMP22 expression levels (Figure 1F). HEC-1A/ PMP22 overexpressed myc-tagged human PMP22, HEC$1 \mathrm{~A} /$ Vector expressed a vector control and baseline levels of endogenous PMP22, and HEC-1A/siRNA expressed PMP22-targeted siRNA and thus, reduced levels of PMP22. In some experiments we also utilized a scrambled siRNA control, which phenotypically resembled the vector control. Based on semi-quantitative analysis, we obtained a $3 \pm 0.2$-fold increase in the levels of PMP22 in the overexpressing cells. In comparison, the siRNA reduced endogenous PMP2 by $50 \pm 5 \%$ (Figure $1 \mathrm{~F}$ ). No difference in PMP22 expression was observed between the vector control and scrambled siRNA control.

\section{Changes in PMP22 expression regulates $\alpha 6$ integrin expression}

We next investigated whether PMP22 expression regulated the surface expression of specific integrin subunits.
Flow cytometry was used to study select integrin expression in HEC-1A/PMP22, HEC-1A/Vector, HEC$1 \mathrm{~A} /$ scrambled control, and HEC-1A/siRNA cells. Overexpression of PMP22 resulted in increased expression of $\alpha 6$ integrin compared to HEC-1A/Vector control cells (Figure 2). Interestingly, a reduction of PMP22 expression with siRNA also reduced the expression of $\alpha 6$ integrin relative to vector control cells. This affect was exclusive to $\alpha 6$ integrin because overexpression of PMP22 did not alter the expression pattern of the integrin $\alpha 2$ subunit (Figure 2). Moreover, HEC-1A/PMP22 inversely modulated the expression of $\alpha \mathrm{v} \beta 3$ integrin. High levels of PMP22 slightly reduced the expression of $\alpha v \beta 3$ integrin, while transfection with PMP22 siRNA slightly increased the expression of this integrin pair (Figure 2). No differences between the vector control and scrambled siRNA controls were observed (data not shown). 
A.
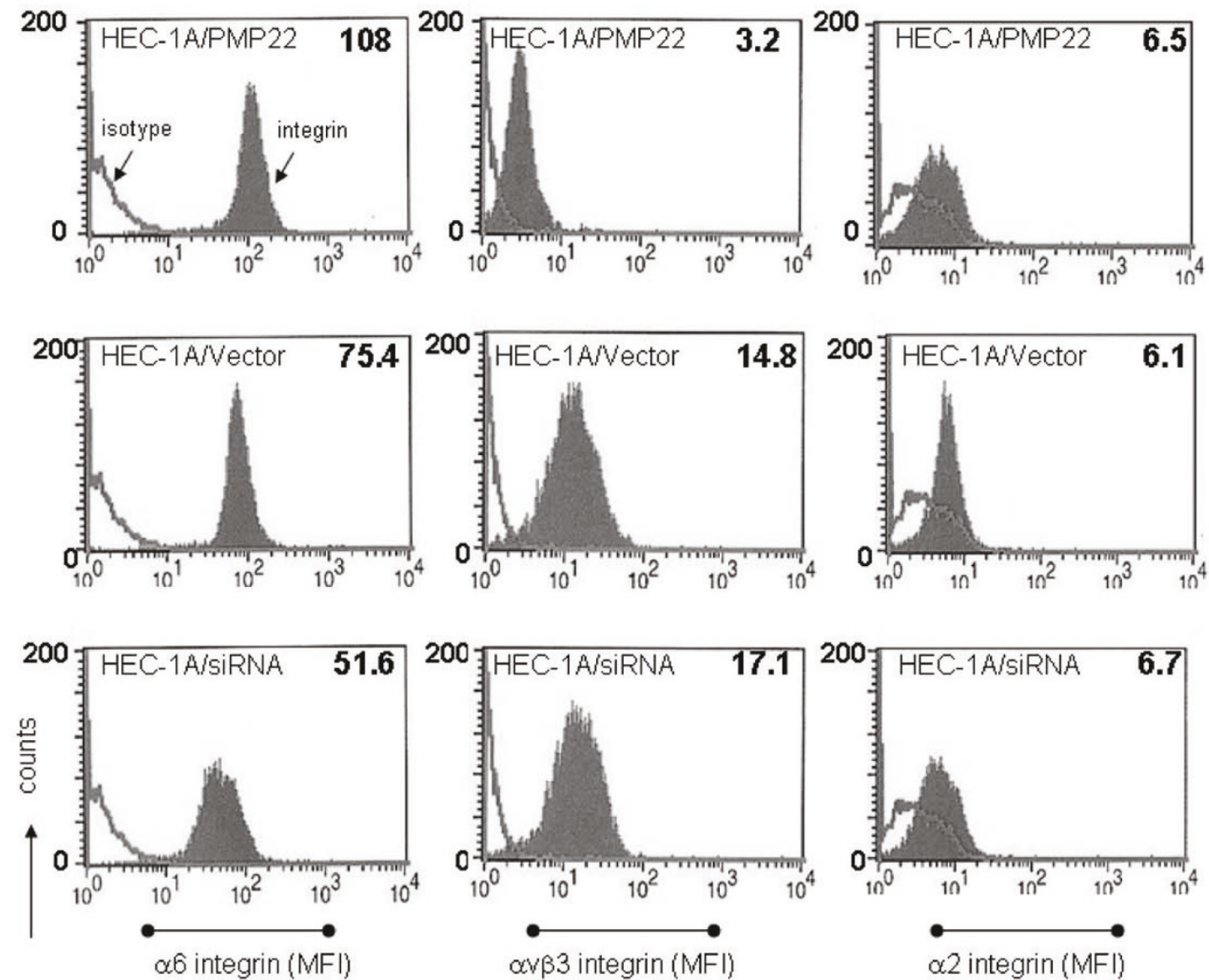

$\alpha \vee \beta 3$ integrin (MFI)

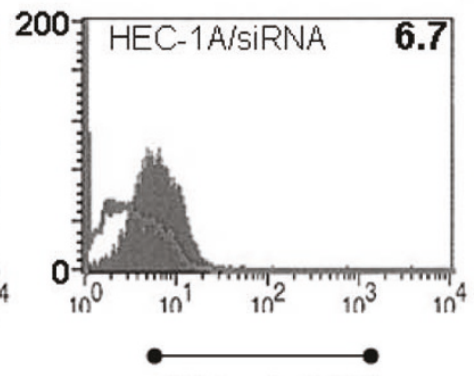

$\alpha 2$ integrin (MFl)

B.

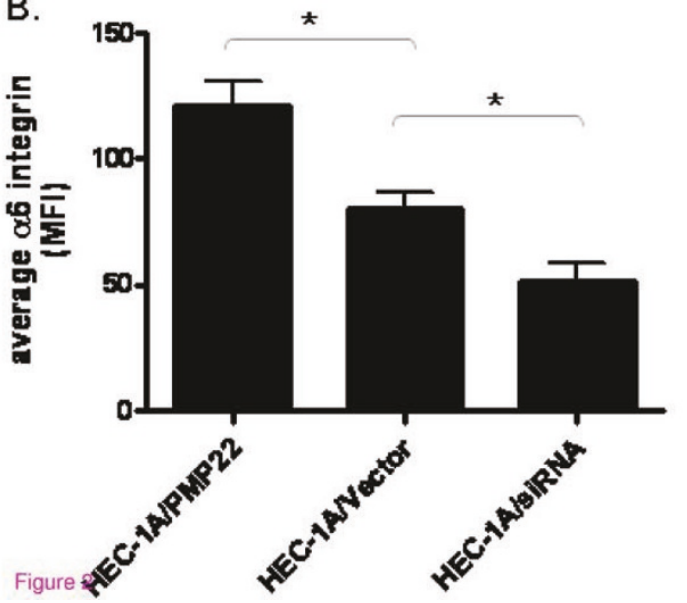

C.

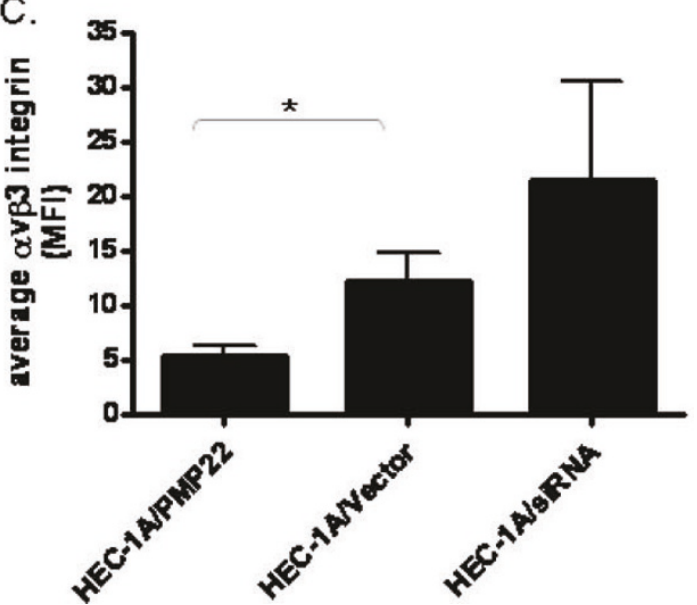

Figure 2 PMP22 expression differentially regulates select integrin pairs. The surface expression of $\alpha 6, \alpha \vee \beta 3$, or $\alpha 2$ integrin in HEC-1A/ PMP22, HEC-1ANector, or HEC-1A/PMP22 siRNA cells was determined using flow cytometry. The MFI was quantitated and tabulated in the top corner of each histogram. Upregulation of PMP22 promoted the surface expression of $\alpha 6$ integrin, while slightly reducing $\alpha \vee \beta 3$ integrin. Reciprocal effects were seen with the PMP22 specific siRNA. In contrast, no change in $\alpha 2$ integrin expression was observed when PMP22 expression was modulated. The experiment was repeated three times, and a representative experiment is shown. Statistical differences between $\alpha 6$ integrin (B) and $\alpha \vee \beta 3$ (C) expression were determined between the three cell lines. *, $p<0.05$; Student's unpaired $t$ test. 
Changes in PMP22 expression influence cell adhesion to extracellular matrix proteins

One important function of integrins is to bind to extracellular matrix proteins. To translate the functional effect of changes in PMP22 expression levels on $\alpha 6$ integrin ligand specificity, HEC-1A/PMP22, HEC-1A/ PMP22 siRNA, HEC-1A/scrambled control, and HEC$1 \mathrm{~A} /$ Vector control cells were tested for their binding capacity to the extracellular matrix laminin. Overexpression of PMP22 resulted in a significant increase in binding to laminin while in contrast, PMP22 siRNA reduced laminin binding (Figure 3A). To confirm that laminin binding was $\alpha 6$ integrin-dependent, HEC-1A cells were

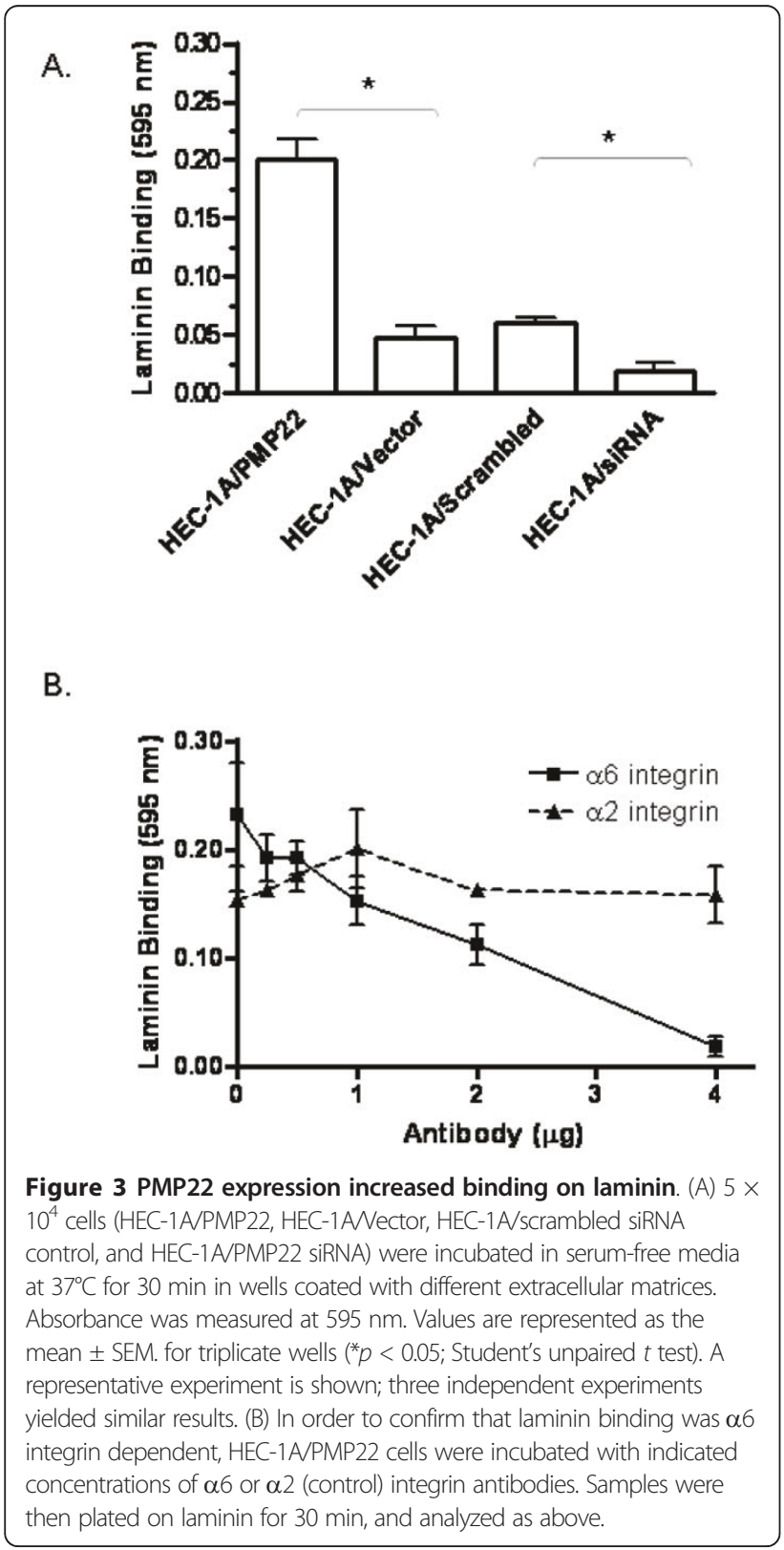

incubated for $30 \mathrm{~min}$ with increasing concentrations of either $\alpha 6$ or $\alpha 2$ integrin blocking antibodies (Figure 3B). PMP22 binding to laminin was specifically disrupted when incubated with $\alpha 6$ integrin antibodies, but was not affected by $\alpha 2$ integrin antibodies. These results strongly suggested that the tetraspan protein PMP22 may help regulate $\alpha 6$ integrin-mediated adhesion.

\section{PMP22 and $\alpha 6$ integrin coimmunoprecipitate}

As the flow cytometry data suggested that expression of $\alpha 6$ integrin was altered by changes in PMP22 expression, we started to characterize this correlation. Initially, we determined if PMP22 and $\alpha 6$ integrin could associate. Immunoprecipitations were performed in HEC-1A/ Vector and HEC-1A/PMP22 cells. In HEC-1A/Vector and HEC-1A/PMP22 overexpressing cells, use of an anti-PMP22 antibody pulled down both $\alpha 6$ integrin and PMP22 (Figure 4A). Concordantly, pull-down with anti$\alpha 6$ integrin antibody resulted in detectable PMP22 and $\alpha 6$ integrin (Figure 4A).

We also utilized confocal microscopy to examine the co-localization of PMP22 and $\alpha 6$ integrin. HEC-1A/ PMP22 and HEC-1A/Vector cells were stained with

A.

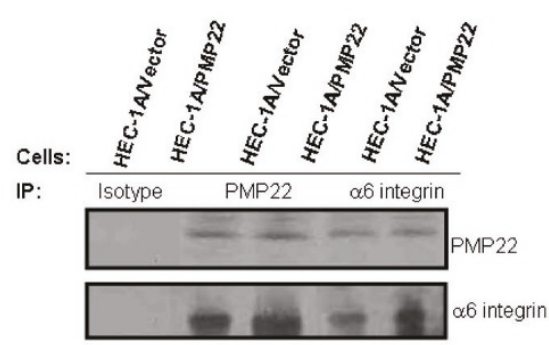

B. HEC-1A/PMP22

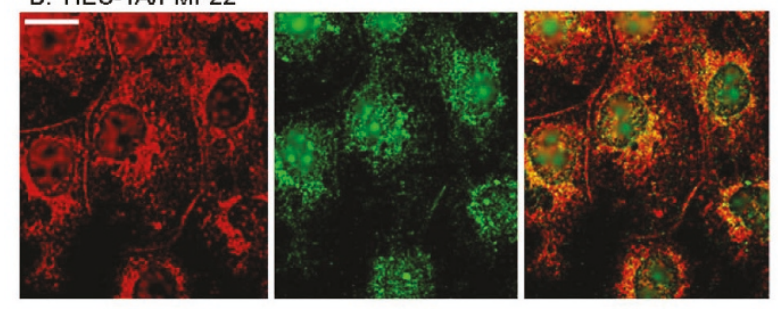

Figure 4 PMP22 and $\alpha 6$ integrin associate with each other HEC-1ANector or HEC-1A/PMP22 cells were lysed in 1\% NP-40 and incubated with PMP22 or $\alpha 6$ integrin antisera. Immunoprecipations were assessed by SDS-PAGE analysis. (A) $\alpha 6$ integrin and PMP22 coimmunoprecipitate in HEC-1ANector and HEC-1A/PMP22 cells when using either PMP22 or the $\alpha 6$ integrin antibody. Normal rabbit sera were used to assess nonspecific pull-down of proteins. (B) Confocal images of HEC-1A/PMP22 cells after co-immunolabeleing with antiPMP22 (Rhodamine) and anti- $\alpha 6$ integrin (clone GOH3; FITC) antibodies. Co-localization of PMP22 protein (Rhodamine) with $\alpha 6$ integrin (FITC) was observed in both intracellular and plasma membrane compartments. Scale bar, $10 \mu \mathrm{M}$. Insets, $50 \mu \mathrm{M}$. 
anti-PMP22 (red) and anti- $\alpha 6$ integrin antibody (green). In HEC-1A/Vector cells, PMP22 and $\alpha 6$ integrin exhibited a similar pattern of expression (data not shown). Specifically, both proteins were largely retained in intracellular compartments, although some protein could be detected on the plasma membrane. Upon overexpression of PMP22 in HEC-1A/PMP22 cells, significant levels of both a6 integrin and PMP22 were visualized (Figure $4 \mathrm{C})$. Both proteins colocalized on the plasma membrane as well as in intracellular compartments. Thus, overexpression of PMP22 results in increased expression of $\alpha 6$ integrin at the plasma membrane, further supporting the association of PMP22 and $\alpha 6$ integrin.

PMP22 is differentially expressed in the menstrual cycle Several studies have suggested that PMP22 is regulated by steroid hormones [20,34]. To examine its expression in the human menstrual cycle, PMP22 mRNA levels in proliferative and secretory endometrium were quantitated using real-time PCR. As shown in Figure 5, PMP22 mRNA levels were significantly down-regulated in secretory endometrium $(\mathrm{n}=6)$ when compared to those in the proliferative phase ( $p=0.02$, Mann Whitney $\mathrm{U}$ test). On average, the PMP22 mean expression level $(1.7 \pm 0.4)$ was 2.5 fold higher than the mean expression of the secretory samples $(0.7 \pm 0.2)$. These results confirm that PMP22 expression is expressed in the endometrium and indicate that PMP22 expression is hormonally regulated in this tissue.

\section{Localization of PMP22 and $\alpha 6$ integrin in human endometrium}

Endometrial sections were stained to characterize the expression of PMP22 in proliferative and secretory

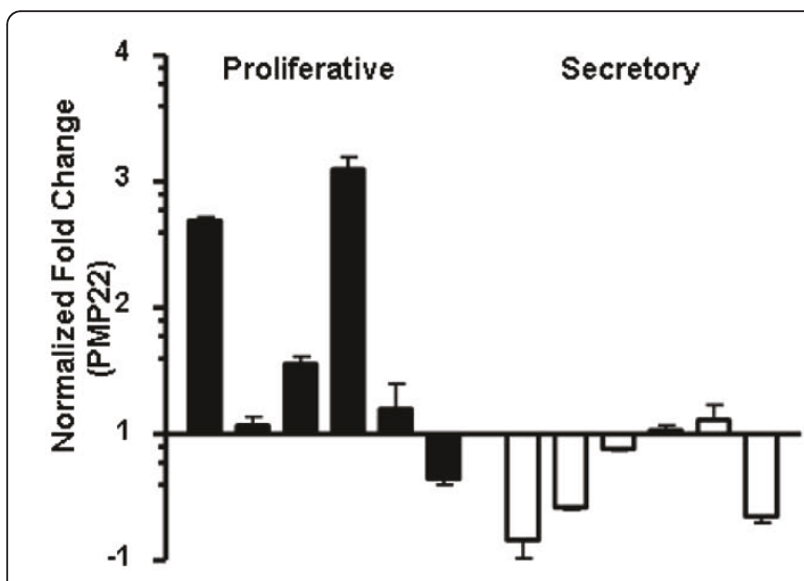

Figure 5 PMP22 mRNA levels inversely correlate in proliferative and secretory phase samples. Normal proliferative $(\mathrm{N}=6)$ and secretory $(\mathrm{N}=6)$ tissue was analyzed for PMP22 expression levels. GAPDH was used to normalize between samples. Significant differences exist in PMP22 expression between normal proliferative and secretory tissues. ${ }^{*} p=0.02$. phases. PMP22 expression exhibited a phase specific expression pattern. High expression of PMP22 was observed in the proliferative phase (Figure 6A), and it was markedly reduced in the secretory phase (Figure 6B). Within proliferative endometrium, intense PMP22 staining was observed in both glandular and luminal epithelium as well as in the stroma (Figure 6A). Moreover, PMP22 localized with the basolateral interface within glandular epithelium (arrow).

To validate the co-expression of PMP22 and $\alpha 6$ integrin in the endometrium, human endometrial tissues were also probed for $\alpha 6$ integrin expression. Concordantly, during the proliferative phase, expression of $\alpha 6$ integrin was detectable in the glandular epithelium, luminal epithelium, and in the surrounding stromal cells (Figure 6C), and its expression was reduced in secretory endometrium (Figure 6D). Moreover, although $\alpha 6$ integrin showed some staining on the apical surface, there was also pronounced expression on the basolateral side during the proliferative phase (Figure $6 \mathrm{~A}$ and $6 \mathrm{C}$, arrows). The specificity of staining for both PMP22 and $\alpha 6$ integrin was confirmed using control rabbit sera on a section of secretory endometrium (Figure 6E). To quantitate the observed differences of PMP22 and $\alpha 6$ integrin expression in the proliferative and secretory phases, 12 normal endometrial samples were scored for intensity and the percentage of cells stained. Both PMP22 and $\alpha 6$ integrin were significantly higher in proliferative compared to secretory endometrium (Figure 6F).

\section{Discussion}

Limited data are available on the role of PMP22 in epithelial cell models and within the endometrium. In this study, we confirm the expression of PMP22 in the endometrium, and show that PMP22 is expressed in human glandular, luminal, and stromal cells of the endometrium. Within the menstrual cycle, PMP22 expression is greater during the proliferative phase as compared to the secretory phase, and this expression correlates with similar changes in $\alpha 6$ integrin expression. Mechanistically, both proteins associate in the same complex as determined by immunoprecipation and colocalize by immunoflorescence. Furthermore, elevation of PMP22 expression in HEC-1A cells increases the expression of $\alpha 6$ integrin; conversely, reduction of PMP22 expression also reduces the levels of $\alpha 6$ integrin. Importantly, these changes in integrin surface expression are functionally relevant as corresponding changes in the level of cell adhesion to the extracellular matrix protein laminin are observed.

We propose that PMP22 expression and association with $\alpha 6$ integrin may be important to maintain endometrial integrity. $\alpha 6$ integrins have an important function 
A.

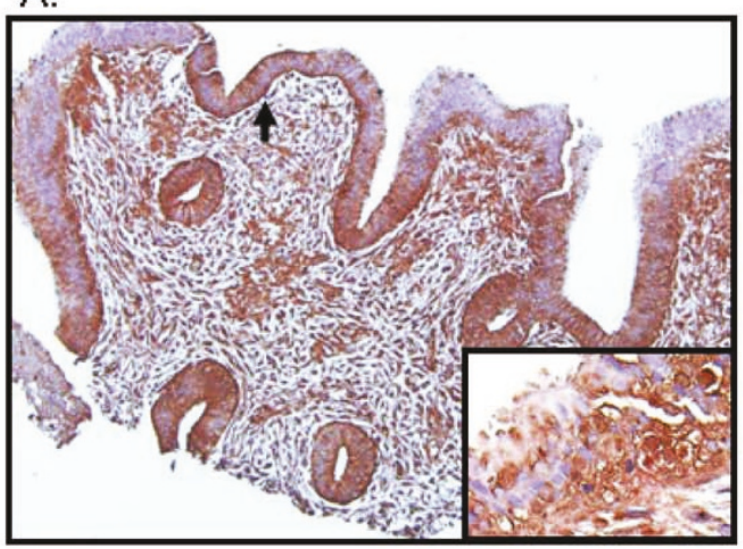

C.

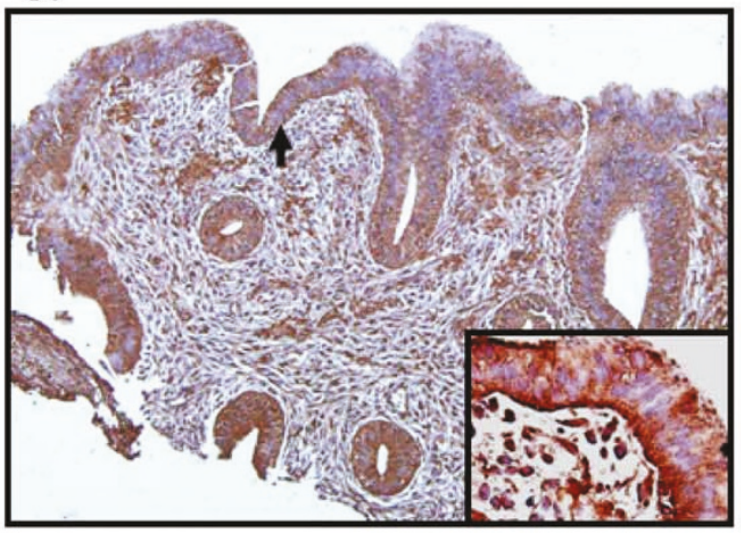

E.

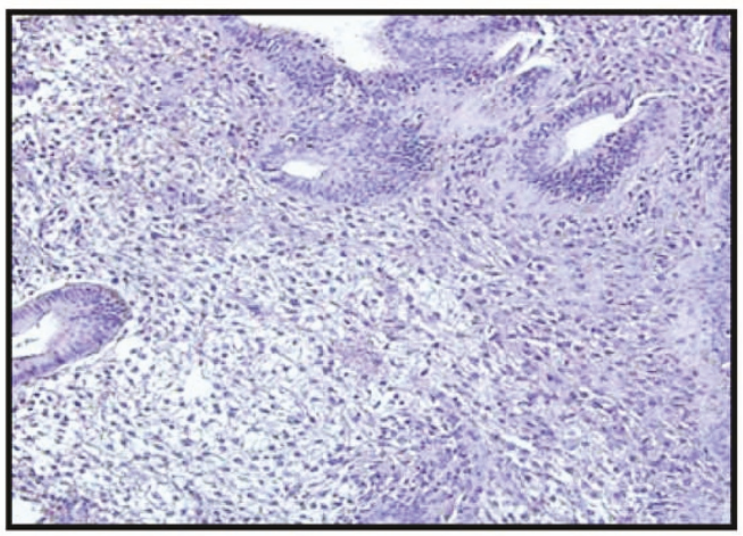

B.

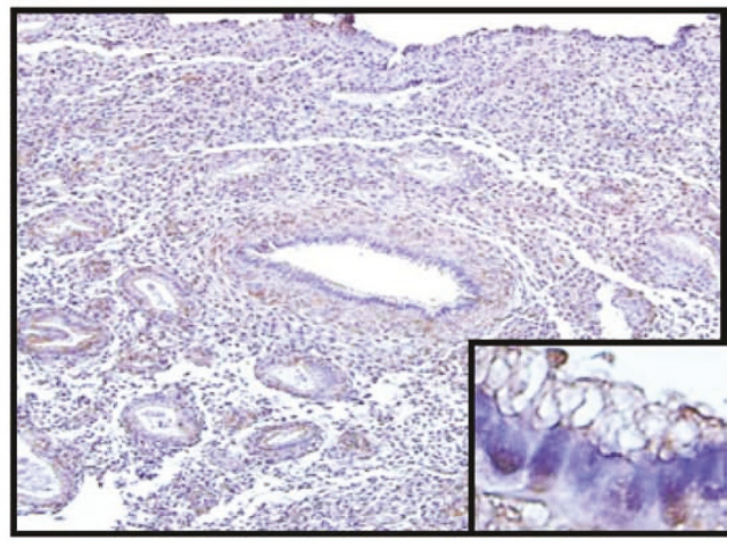

D.

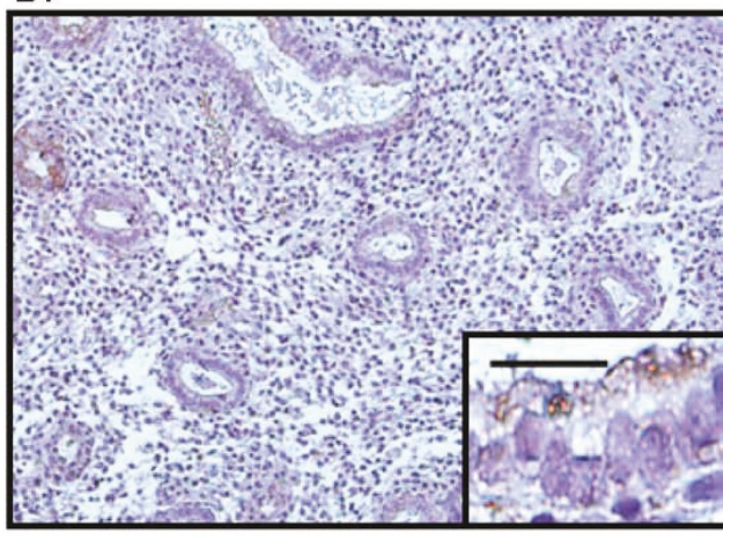

$\mathrm{F}$

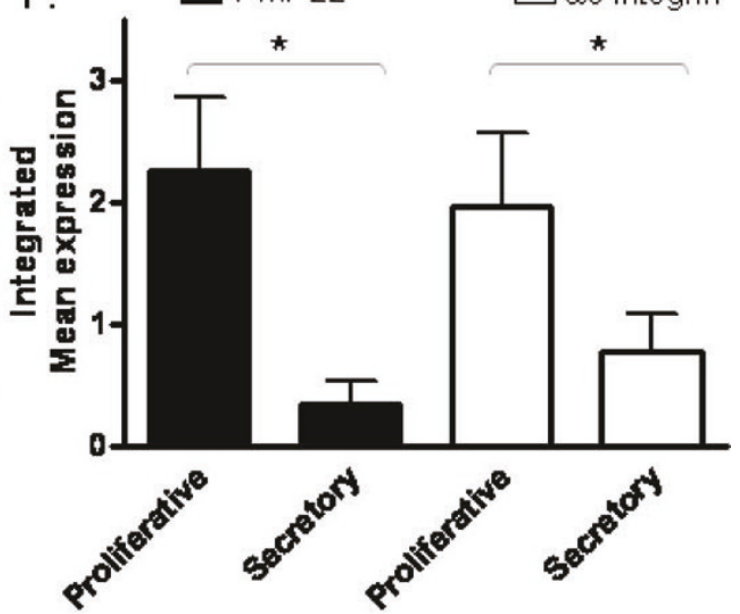

Figure 6 PMP22 and $\alpha 6$ integrin share a similar pattern of expression in human endometrium. (A, C) Normal human proliferative endometrium was stained by immunohistochemistry for either PMP22 or $\alpha 6$ integrin, respectively. Bound antibodies were visualized using DAB, and nuclei counterstained using hemotoxylin. Magnification: 100X. Insets depict a 400X enlargement of glandular epithelium. (B, D) Normal human secretory endometrium was stained by immunohistochemistry for either PMP22 or $\alpha 6$ integrin as above. Magnification: 100X. Insets depict a 400X enlargement of glandular epithelium. (E) Normal human proliferative endometrium was stained as above using non-specific control rabbit sera. (F) The mean integrated intensity of PMP22 and $\alpha 6$ integrin protein expression was quantitated for each sample; $\mathrm{N}=6$ per group. The error bars represent the standard error of the mean. ${ }^{*} p<0.05$. 
in not only the attachment of cells to the extracellular matrix, but also in the induction of cell migration and invasion [35,36]. Within the endometrium, $\alpha 6$ integrin has been shown to dimerize with both $\beta 1$ and $\beta 4$ integrin. Although it is not known if PMP22 preferentially associates with $\alpha 6 \beta 1$ or $\alpha 6 \beta 4$ integrins, the localization of PMP22 on the basal surface of endometrial cells suggests an association with $\alpha 6 \beta 4$ integrin [35]. This correlation is supported by recent studies in clone A colonic carcinoma cells showing that PMP22 forms a complex with $\alpha 6 \beta 4$ integrin [18]. Thus, it is possible that PMP22 helps stabilize or anchor $\alpha 6 \beta 4$ integrins on endometrial epithelial cells to the underlying basement membrane, which is known to be comprised of laminin and collagen $[37,38]$ Intriguingly, laminin expression is rich during the proliferative phase and reduced during the secretory phase [38]. Additional experiments will be needed to confirm the association and the specificity of PMP22 and $\alpha 6$ integrin within endometrial cells.

PMP22 belongs to the GAS3 family of tetraspan proteins, and each family member shares similar primary and secondary structures, with four relatively conserved transmembrane regions and two significant extracellular loops $[39,40]$. Interestingly, another GAS3 family member EMP2 has been detected in the endometrium $[25,28,41]$. With regard to EMP2 and PMP22, a unique regulatory phenotype has been observed within endometrial cells. Whereas PMP22 is expressed predominantly in proliferative endometrium, EMP2 expression is greater in the secretory phase [28]. Moreover, changes in PMP22 and EMP2 expression appear to modulate different integrin pairs. Overexpression of EMP2 results in the increase of $\alpha v \beta 3$-integrin whereas elevation of PMP22 selectively increases the expression of $\alpha 6$ integrin [25]. It is thus intriguing to speculate that this divergent affect on integrin expression may be translated to distinct effects on cellular function.

Importantly, our study confirms that steroid hormones can regulate the expression of PMP22 and concordantly the $\alpha 6$ integrin in non-neuronal tissue. Several studies have shown that in Schwann cells, PMP22 can be hormonally activated. Both glucocortosteroids and $5 \alpha$ androstan- $3 \alpha, 17 \beta$-diol ( $3 \alpha$-diol), a metabolite of dihydrotestosteone, has been shown to transiently upregulate PMP22 1A mRNA levels [20,21]. Moreover, anti-progesterone treatments have been shown to improve the phenotype for CMT1A through the specific reduction of PMP22 in Schwann cells [22,23]. Our results suggest that the regulation of PMP22 $1 \mathrm{~A}$ and $1 \mathrm{~B}$ is different. Given its high expression in the proliferative phase, we would predict that estrogen may upregulate the expression of the PMP22 1B transcript in the endometrium. Additional experiments will be needed to characterize differences in the promoters of each transcript.
Finally, our data suggest that elevated or reduced PMP22 levels could result in an altered repertoire of integrin isoform expression and perhaps specifically with $\alpha 6$ integrin. As dysregulation of $\alpha 6$ integrin has been implicated in disease biology of the endometrium, PMP22 may be an underappreciated potential target for diseases such as infertility, endometriosis, and endometrial cancer $[35,42,43]$.

\section{Abbreviations}

PMP22: peripheral myelin protein-22; EMP2: epithelial membrane protein 2; GAS3: growth arrest specific 3.

\section{Acknowledgements}

Support for this project was provided by NIH HD48540 (JB), NIH CA131756 (MW), The NCl Early Detection Research Network NCl CA86366 (LG) and the American Cancer Society \# RSG-03-160-01-LIB (LG).

\section{Author details}

${ }^{1}$ Department of Pathology and Laboratory Medicine, University of California Los Angeles, California 90095, USA. ${ }^{2}$ Department of Neuroscience, McKnight Brain Institute, University of Florida, Gainesville, FL 32610, USA. ${ }^{3}$ Department of Ophthalmology, University of California, Los Angeles, California 90095, USA. ${ }^{4}$ Jonsson Comprehensive Cancer Center, University of California, Los Angeles, California 90095, USA.

\section{Authors' contributions}

RGR and DS carried out the immunoprecipitation and microscopy experiments. $\mathrm{CPH}$ performed the real time PCR and immunohistochemistry experiments. SA and LN participated in the design of the study. LG and MW conceived of the study, and JB and LKG participated in its design and coordination. All authors read and approved the final manuscript.

\section{Competing interests}

The authors declare that they have no competing interests.

Received: 18 November 2010 Accepted: 25 April 2011

Published: 25 April 2011

\section{References}

1. Suter U, Snipes GJ, Schoener-Scott R, Welcher AA, Pareek S, Lupski JR, Murphy RA, Shooter EM, Patel PI: Regulation of tissue-specific expression of alternative peripheral myelin protein-22 (PMP22) gene transcripts by two promoters. J Biol Chem 1994, 269:25795-25808.

2. Hai M, Bidichandani SI, Patel PI: Identification of a positive regulatory element in the myelin-specific promoter of the PMP22 gene. J Neurosci Res 2001, 65:508-519.

3. Garbay B, Boiron-Sargueil F, Cassagne C: Expression of the exon 1Acontaining PMP22 transcript is altered in the trembler mouse. Neurosci Lett 1995, 198:157-160

4. Ohsawa Y, Murakami T, Miyazaki Y, Shirabe T, Sunada Y: Peripheral myelin protein 22 is expressed in human central nervous system. J Neurol Sci 2006, 247:11-15.

5. Patel PI, Roa BB, Welcher AA, Schoener-Scott R, Trask BJ, Pentao L, Snipes GJ, Garcia CA, Francke U, Shooter EM, et al: The gene for the peripheral myelin protein PMP-22 is a candidate for Charcot-MarieTooth disease type 1A. Nat Genet 1992, 1:159-165.

6. Pareek S, Suter U, Snipes GJ, Welcher AA, Shooter EM, Murphy RA: Detection and processing of peripheral myelin protein PMP22 in cultured Schwann cells. J Biol Chem 1993, 268:10372-10379.

7. Notterpek L, Snipes GJ, Shooter EM: Temporal expression pattern of peripheral myelin protein 22 during in vivo and in vitro myelination. Glia 1999, 25:358-369.

8. Valentijn LJ, Bolhuis PA, Zorn I, Hoogendijk JE, van den Bosch N Hensels GW, Stanton VP Jr, Housman DE, Fischbeck KH, Ross DA, et al: The peripheral myelin gene PMP-22/GAS-3 is duplicated in Charcot-MarieTooth disease type 1A. Nat Genet 1992, 1:166-170. 
9. Naef R, Suter U: Many facets of the peripheral myelin protein PMP22 in myelination and disease. Microsc Res Tech 1998, 41:359-371.

10. Roux KJ, Amici SA, Fletcher BS, Notterpek L: Modulation of epithelial morphology, monolayer permeability, and cell migration by growth arrest specific 3/peripheral myelin protein 22. Mol Biol Cell 2005, 16:1142-1151.

11. Li J, Ghandour K, Radovanovic D, Shy RR, Krajewski KM, Shy ME, Nicholson GA: Stoichiometric alteration of PMP22 protein determines the phenotype of hereditary neuropathy with liability to pressure palsies. Arch Neurol 2007, 64:974-978.

12. Chance PF, Alderson MK, Leppig KA, Lensch MW, Matsunami N, Smith B, Swanson PD, Odelberg SJ, Disteche CM, Bird TD: DNA deletion associated with hereditary neuropathy with liability to pressure palsies. Cell 1993, 72:143-151.

13. Zoidl G, Blass-Kampmann S, D'Urso D, Schmalenbach C, Muller HW: Retroviral-mediated gene transfer of the peripheral myelin protein PMP22 in Schwann cells: modulation of cell growth. EMBO J 1995, 14:1122-1128.

14. Schneider C, King RM, Philipson L: Genes specifically expressed at growth arrest of mammalian cells. Cell 1988, 54:787-793.

15. Brancolini C, Marzinotto S, Edomi P, Agostoni E, Fiorentini C, Muller HW, Schneider C: Rho-dependent regulation of cell spreading by the tetraspan membrane protein Gas3/PMP22. MolBio/Cell 1999, 10:2441-2459.

16. Wilson HL, Wilson SA, Surprenant A, North RA: Epithelial membrane proteins induce membrane blebbing and interact with the P2X7 receptor C terminus. J Biol Chem 2002, 277:34017-34023.

17. Notterpek L, Roux KJ, Amici SA, Yazdanpour A, Rahner C, Fletcher BS: Peripheral myelin protein 22 is a constituent of intercellular junctions in epithelia. Proc Natl Acad Sci USA 2001, 98:14404-14409.

18. Amici SA, Dunn WA Jr, Murphy AJ, Adams NC, Gale NW, Valenzuela DM, Yancopoulos GD, Notterpek L: Peripheral myelin protein 22 is in complex with alpha6beta4 integrin, and its absence alters the Schwann cell basal lamina. J Neurosci 2006, 26:1179-1189.

19. Desarnaud F, Do Thi AN, Brown AM, Lemke G, Suter U, Baulieu EE, Schumacher M: Progesterone stimulates the activity of the promoters of peripheral myelin protein-22 and protein zero genes in Schwann cells. JNeurochem 1998, 71:1765-1768.

20. Melcangi RC, Magnaghi V, Galbiati M, Ghelarducci B, Sebastiani L, Martini L: The action of steroid hormones on peripheral myelin proteins: a possible new tool for the rebuilding of myelin? I Neurocytol 2000, 29:327-339.

21. Desarnaud F, Bidichandani S, Patel PI, Baulieu EE, Schumacher M: Glucocorticosteroids stimulate the activity of the promoters of peripheral myelin protein-22 and protein zero genes in Schwann cells. Brain Res 2000, 865:12-16.

22. Meyer zu Horste G, Prukop T, Liebetanz D, Mobius W, Nave KA, Sereda MW: Antiprogesterone therapy uncouples axonal loss from demyelination in a transgenic rat model of CMT1A neuropathy. Ann Neurol 2007, 61:61-72.

23. Sereda MW, Meyer zu HG, Suter U, Uzma N, Nave KA: Therapeutic administration of progesterone antagonist in a model of Charcot-MarieTooth disease (CMT-1A). NatMed 2003, 9:1533-1537.

24. Yanaihara A, Otsuka Y, Iwasaki S, Aida T, Tachikawa T, Irie T, Okai T: Differences in gene expression in the proliferative human endometrium. Fertil Steril 2005, 83(Suppl 1):1206-1215.

25. Wadehra M, Forbes A, Pushkarna N, Goodglick L, Gordon LK, Williams CJ, Braun J: Epithelial membrane protein-2 regulates surface expression of alphavbeta3 integrin in the endometrium. Dev Biol 2005, 287:336-345.

26. Wadehra M, Braun J, Goodglick L: One Step RT-PCR for Screening Microdissected Tissue. Biotechniques 2002, 32:242-247.

27. Schmittgen TD, Livak KJ: Analyzing real-time PCR data by the comparative C(T) method. Nat Protoc 2008, 3:1101-1108

28. Wadehra M, Mainigi M, Morales SA, Rao RG, Gordon LK, Williams CJ, Braun J: Steroid hormone regulation of EMP2 expression and localization in the endometrium. Reprod Biol Endocrinol 2008, 6:15.

29. Wadehra M, Sulur GG, Braun J, Gordon LK, Goodglick L: Epithelial Membrane Protein-2 is expressed in discrete anatomical regions of the eye. Experimental and Molecular Pathology 2003, 74:106-112.

30. Wadehra M, Iyer R, Goodglick L, Braun J: The tetraspan protein epithelial membrane protein- 2 interacts with beta 1 integrins and regulates adhesion. J Biol Chem 2002, 277:41094-41100.
31. Aumailley $M$, Timpl $R$, Sonnenberg A: Antibody to integrin alpha 6 subunit specifically inhibits cell-binding to laminin fragment 8 . ExpCell Res 1990, 188:55-60.

32. Mendrick DL, Kelly DM, duMont SS, Sandstrom DJ: Glomerular epithelial and mesangial cells differentially modulate the binding specificities of VLA-1 and VLA-2. Lab Invest 1995, 72:367-375.

33. Maier $M$, Castagner $F$, Berger $P$, Suter U: Distinct elements of the peripheral myelin protein 22 (PMP22) promoter regulate expression in Schwann cells and sensory neurons. Mol Cell Neurosci 2003, 24:803-817.

34. Schumacher M, Guennoun R, Mercier G, Desarnaud F, Lacor P, Benavides J, Ferzaz B, Robert F, Baulieu EE: Progesterone synthesis and myelin formation in peripheral nerves. Brain ResBrain ResRev 2001, 37:343-359.

35. Vernet-Tomas Mdel M, Perez-Ares CT, Verdu N, Fernandez-Figueras MT, Molinero JL, Carreras R: The depolarized expression of the alpha-6 integrin subunit in the endometria of women with endometriosis. J Soc Gynecol Investig 2006, 13:292-296.

36. Beliard A, Donnez J, Nisolle M, Foidart JM: Localization of laminin, fibronectin, E-cadherin, and integrins in endometrium and endometriosis. Fertil Steril 1997, 67:266-272.

37. Maatta M, Salo S, Tasanen K, Soini Y, Liakka A, Bruckner-Tuderman L, AutioHarmainen H: Distribution of basement membrane anchoring molecules in normal and transformed endometrium: altered expression of laminin gamma2 chain and collagen type XVII in endometrial adenocarcinomas. J Mol Histol 2004, 35:715-722

38. Tanaka T, Wang C, Umesaki N: Remodeling of the human endometrial epithelium is regulated by laminin and type IV collagen. Int I Mol Med 2009, 23:173-180.

39. D'Urso D, Muller HW: Ins and outs of peripheral myelin protein-22: mapping transmembrane topology and intracellular sorting. J Neurosci Res 1997, 49:551-562.

40. Taylor V, Welcher AA, Program AE, Suter U: Epithelial membrane protein-1, peripheral myelin protein 22 , and lens membrane protein 20 define a novel gene family. J Biol Chem 1995, 270:28824-28833.

41. Wadehra M, Dayal M, Mainigi M, Ord T, Iyer R, Braun J, Williams CJ: Knockdown of the tetraspan protein epithelial membrane protein-2 inhibits implantation in the mouse. Dev Biol 2006, 292:430-441.

42. Rai V, Hopkisson J, Kennedy S, Bergqvist A, Barlow DH, Mardon HJ: Integrins alpha 3 and alpha 6 are differentially expressed in endometrium and endometriosis. J Pathol 1996, 180:181-187.

43. Lessey BA, Damjanovich L, Coutifaris C, Castelbaum A, Albelda SM, Buck CA: Integrin adhesion molecules in the human endometrium. Correlation with the normal and abnormal menstrual cycle. J Clin Invest 1992 90:188-195.

doi:10.1186/1477-7827-9-56

Cite this article as: Rao et al.: Peripheral myelin protein-22 (PMP22) modulates alpha 6 integrin expression in the human endometrium. Reproductive Biology and Endocrinology 2011 9:56.

\section{Submit your next manuscript to BioMed Central and take full advantage of:}

- Convenient online submission

- Thorough peer review

- No space constraints or color figure charges

- Immediate publication on acceptance

- Inclusion in PubMed, CAS, Scopus and Google Scholar

- Research which is freely available for redistribution 